\title{
Responses of lamb nucleus of the solitary tract neurons to chemical stimulation of the epiglottis
}

\author{
Robert D. Sweazey ${ }^{1}$ and Robert M. Bradley ${ }^{1,2}$ \\ 'Department of Oral Biology, University of Michigan, School of Dentistry, Ann Arbor, MI 48109 (U.S.A.) and \\ 'Department of Physiology. The University of Michigan, School of Medicine, Ann Arbor, MI 48109 (U.S.A.)
}

(Accepted 7 July 1987)

Key words: Sheep; Response pattern; Chemoreception; Epiglottis; Nucleus of the solitary tract; Off response; Superior laryngeal nerve; Upper airway

\begin{abstract}
Previous research has shown that applications of chemical stimuli to the epiglottis produced distinct patterns of activity in the lamb superior laryngeal nerve. To determine the response characteristics of second-order neurons, we recorded from single cells in the lamb nucleus of the solitary tract (NST) while stimulating the epiglottis with $0.5 \mathrm{M} \mathrm{KCl}, \mathrm{NH}_{4} \mathrm{Cl}, \mathrm{NaCl}, \mathrm{LiCl}$, distilled water, $0.005 \mathrm{M}$ citric acid and $0.01 \mathrm{~N} \mathrm{HCl}$. Most neurons responded to more than one of the chemical solutions. The order of effective stimuli was $\mathrm{KCl}$ $=\mathrm{NH}_{4} \mathrm{Cl}>$ distilled water $>\mathrm{HCl}>$ citric acid $>\mathrm{NaCl}>\mathrm{LiCl}$. An analysis of the variation in response frequency over time found that different chemical stimuli produced significantly different response patierns in NST neurons. A comparison of the mean neural response profiles of NST neurons and superior laryngeal nerve fibers for each of the stimuli found that only the response profiles elicited by $\mathrm{NH}_{4} \mathrm{Cl}$ were significantly different. In addition to their responses to chemical solutions, almost one-third of the NST neurons responded to the rinse following application of at least some of the stimuli and $80 \%$ of the neurons were excited by mechanical stimulation of the epiglottis with a soft brush. Also, a small number of neurons exhibited a rhythmic response coordinated with respiration. The majority of recording sites were located in areas of the NST linked to swallowing and respiration suggesting that the response patterns of NST neurons elicited by chemical stimulation of receptors on the epiglottis may play a role in upper airway reflexes.
\end{abstract}

\section{INTRODUCTION}

Physiological studies have shown that stimulation of structures in the upper airway evokes a number of protective reflexes like swallowing, apnea and coughing ${ }^{8.16,23.30,31 \cdot 36,37.52 .53}$. These reflexes can be evoked by a variety of stimulus types including chemical and mechanical ${ }^{8,31,35,47.52,57}$. Although the receptor types responsible for eliciting these reflexes are at present unclear, some studies have suggested that the receptors mediating chemically-elicited reflexes are taste buds ${ }^{10,12.13 .30 .35 .51 .52}$. The majority of taste buds in the upper airway are located on the laryngeal surface of the epiglottis and are innervated by the superior laryngeal nerve (SLN). Recordings from the SLN in lamb, sheep and cat have shown that when chemical solutions are placed on the epiglottis, the patterns of activity elicited are distinctive for the dif- ferent chemical stimuli ${ }^{13.50}$. These patterns of information are conveyed to the nucleus of the solitary tract (NST) by fibers of the SLN ${ }^{14.27 .29 .44 .54}$.

A number of studies have described the responses of neurons in the NST to electrical stimulation of the SLN $^{7.14 .27 .44 .45}$; however, little information exists concerning the responses of NST neurons to chemical stimulation of the epiglottis. In lambs the structure and number of taste buds on the epiglottis have been described ${ }^{12}$, there is information on reflex responses to chenticals applied in the laryn $\mathrm{x}^{30.35}$, and the responses of SLN fibers to simuiation of the epiglottis with chemicals have been previously reported $^{13}$. Consequently, lambs were used in our investigation of the responses of NST neurons to stimulation of the epiglottis with a variety of chemical solutions. Two questions were of special interest. First was whether the stimulus response patterns seen in

Correspondence: R.D. Sweazey, Department of Oral Biology, University of Michigan. Ann Arbor, MI 48109, U.S.A. 
lamb and sheep $\mathrm{SLN}^{13}$ were maintained at the level of the NST. Second was whether the neural response patterns observed in the NST were sufficient to discriminate among the cifferent chemical stimuli.

\section{MATERIALS AND METHODS}

\section{Surgical preparation}

Twenty-three Suffolk lambs (aged 30-80 days) were first anesthetized with an intravenous injection of sodium pentobarbitol $(20 \mathrm{mg} / \mathrm{kg})$ and then placed on a heating pad adjusted to maintain body temperature at $39^{\circ} \mathrm{C}$, which was monitored by rectal probe. The jugular vein was cannulated for the administration of supplemental anesthetics and a tracheostorny performed close to the sternal notch.

A midline incision was made from the first tracheal cartilage to the base of the epiglottis and the interior of the larynx was exposed by retraction. The epiglottis was reflected caudally into the open larynx using a laryngoscope so that its iaryngeal surface was visible through the incision, and the epiglottis was held in place with a suture ${ }^{50}$. The epiglottis was covered with saline-soaked cotton until stimulation commenced and the pharynx and esophagus were obdurated by an air-filled balloon. This balloon prevented solutions from being ingested or entering the oral and nasal cavities.

The animal was placed in a prone position and the head fixed in a stereotaxic frame. The dorsal surface of the medulla from obex to the dorsal cochlear nucleus was exposed by removing the overlying muscles and occipital bone, and the caudal cerebellum was aspirated. The stereotaxic frame was then rotated $45^{\circ}$ from horizontal to permit stimulation of the epiglottis from below while recording from single neurons in the brainstem.

\section{Neurophysiology}

Single neurons were isolated using epoxy-coated tungsten microelectrodes (2-3 M $\Omega$ impedance). The neural activity was amplified, displayed on an oscilloscope and monitored with an audio amplifier. Neural data were stored on one channel of a magnetic tape recorder with voice cues of experimental procedure on a second channel. Neural activity was classified as coming from a single neuron on the basis of an action potential of constant amplitude and waveform. Using stimuli previously shown to be effective for lamb, sheep and cat SLN fibers ${ }^{13.50}$, we located NST neurons by applying a $0.5 \mathrm{M}$ solution of $\mathrm{KCl}$ and a $0.01 \mathrm{~N}$ solution of $\mathrm{HCl}$ to the epiglottis, or by stroking the epiglottis with a small brush. If a mechanically sensitive neuron was identified, chemicals were then applied to establish chemosensitivity. Mechanically sensitive neurons which were not chemosensitive were not analyzed further.

\section{Stimuli}

Chemical stimuli were $0.5 \mathrm{M} \mathrm{KCl}, \mathrm{NH}_{4} \mathrm{Cl}, \mathrm{NaCl}$ and $\mathrm{LiCl}, 0.005 \mathrm{M}$ citric acid, $0.01 \mathrm{~N} \mathrm{HCl}$ and distilled water. These stimuli were chosen so that direct comparisons could be made with previously reported data on responses from lamb SLN to chemical stimulation of the epiglottis ${ }^{13}$. Because water elicits a neural response in the SLN when applied to the epiglottis, all chemicals were dissolved in $0.154 \mathrm{M} \mathrm{NaCl}$ which elicits minimal activity in the $\operatorname{SLN}^{9,13,24,50}$. This concentration of $\mathrm{NaCl}$ was also used as a rinse solution to remove chemical stimuli from the epiglottis.

Syringes $(10 \mathrm{ml})$ fitted with 19-gauge needles were used to deliver $10 \mathrm{ml}$ of a stimulus solution to the exposed epiglottis. Each chemical stimulus solution remained on the epiglottis for at least $20 \mathrm{~s}$ and was then removed by application of $40 \mathrm{ml}$ of the $0.154 \mathrm{M} \mathrm{NaCl}$ rinse solution from a $50 \mathrm{ml}$ syringe. Stimuli were given in the following sequence: $10 \mathrm{ml} 0.154 \mathrm{M} \mathrm{NaCl}$ rinse, $\mathrm{KCl}, \mathrm{NH}_{4} \mathrm{Cl}, \mathrm{NaCl}, \mathrm{LiCl}, 10 \mathrm{ml}$ rinse, $\mathrm{KCl}$, distilled water, citric acid, $\mathrm{HCl}, 10 \mathrm{ml}$ rinse, $\mathrm{KCl}$. At least 2 min were allowed to pass between stimulations to prevent cumulative adaptation ${ }^{49}$. Whenever possible this total sequence of stimuli was repeated. The stimulation sequence was administered twice to $40 \%$ of the neurons.

Previous recordings from the SLN found that $\mathrm{KCl}$ elicit: $d$ responses in the majority of fibers ${ }^{13}$ so it was used as the standard in the present study and applied 3 times in the stimulation sequence to monitor the stability of the preparation. In addition to applications of test stimuli and the subsequent rinses, $10 \mathrm{ml}$ of rinse solution from a $10 \mathrm{ml}$ syringe was applied during the stimulation sequence before each application of $\mathrm{KCl}$ (see above). These $10 \mathrm{ml}$ rinses were used as a control to determine those portions of the responses due only to the mechanical effects of flowing a solution over the epiglottis. 


\section{Histology}

Following completion of the stimulus sequence the location of the recording site was marked with a small lesion (direct current, 35 $\mu \mathrm{A}$ for 3-5 s). At the end of the experiment the animal was given an overdose of pentobarbitol and perfused through the carotid arteries with buffered saline followed by $10 \%$ buffered formalin. The brainstem from obex to the inferior colliculus was removed and stored in $30 \%$ sucroseformalin until sectioned. The brain was cut coronally in $40 \mu \mathrm{m}$ secuns and mounted on slides coated with chrom-alum. The tissue was then stained using the Klüver-Barrera technique ${ }^{34}$, and recording sites were marked on standard drawings of the lamb brainstem.

\section{Data analysis}

Recorded neural impulses were converted into standard electrical impulses using a window discriminator; the interval between pulses in milliseconds was measured with a microcomputer ${ }^{11}$, and this information was then converted to frequencies (impulses/s). In order to analyze only that portion of the response due to chemical stimulation, the mean spontaneous frequency of the neuron and the mean response frequency due to the mechanical effects of stimulus flow over the epiglottis were subtracted from the total response. Therefure, the activity analyzed represents responses to chemical stimulation only. The mean spontaneous frequency was calculated by averaging the frequencies from $5 \mathrm{~s}$ periods before and after each chemical stimulation. The mean response frequency due to flow was determined by averaging the responses across the 3 rinses applied during the stimulation sequence. For those neurons which received a repeated presentation of the stimuli, the response was the average of these repeated presentations.

The presence of a chemical response was defined as an increase in average frequency during any 5 sequential seconds of the stimulation period that exceeded the mean \pm 2 S.D. of the spontaneous activity. Of the 36 isolated neurons, 35 were excitatory and one was inhibitory. Because of the small number of inhibitory responses observed in the present study, this one neuron was not included in the remaining analyses.

In addition to the responses to the chemical stimu- li, some neurons displayed an increase in their response to the rinse following the application of certain chemical solutions. In order to investigate these off responses, we subtracted the mean activity of the last $5 \mathrm{~s}$ of response to the preceding chemical stimulus and the mechanical activity due to flow from each post-stimulus rinse. An off response was defined as an increase in the average frequency during any 5 sequential seconds of the post-stimulus rinse that was 2 S.D.s above the mean response frequency of the rinse itself.

\section{Statistical analyses}

To determine whether individual chemicals produced reliably different response patterns we compared pairs of chemical response profiles across neurons using a technique described previously ${ }^{13}$. In short, difference profiles were calculated for all pairs of stimuli within each neuron. Using these difference profiles, comparisons were then made between chemical pairs across neurons using the Hotelling's $T^{2}$-test ${ }^{40}$. These comparisons were performed on the first and last $10 \mathrm{~s}$ of the response to ascertain the contribution of the early and late portions of the response patterns.

To statistically compare the neural response patterns recorded in the NST with those previously reported for the $\mathrm{SLN}^{13}$, a one-sample profile analysis ${ }^{40}$ was conducted between the corresponding stimulus pairs on the last $19 \mathrm{~s}$ of the response. The first second of response was discarded from the analysis because large differences were noted which were due to a difference in stimulation techniques between the two studies. In the present study solutions were delivered via a syringe fitted with a 19-gauge needle producing a fast flow velocity. Solutions were delivered via a gravity flow system at a slower velocity in previous studies of the SLN ${ }^{13}$. Studies have shown that the velocity of stimulus flow is important in the early phase of the neural response to chemical stimulation suggesting that observed differences in the early portions of the responses were due to differences in stimulus delivery ${ }^{48}$.

\section{RESULTS}

\section{Anatomical organization}

The locations of recording sites of the 35 single 

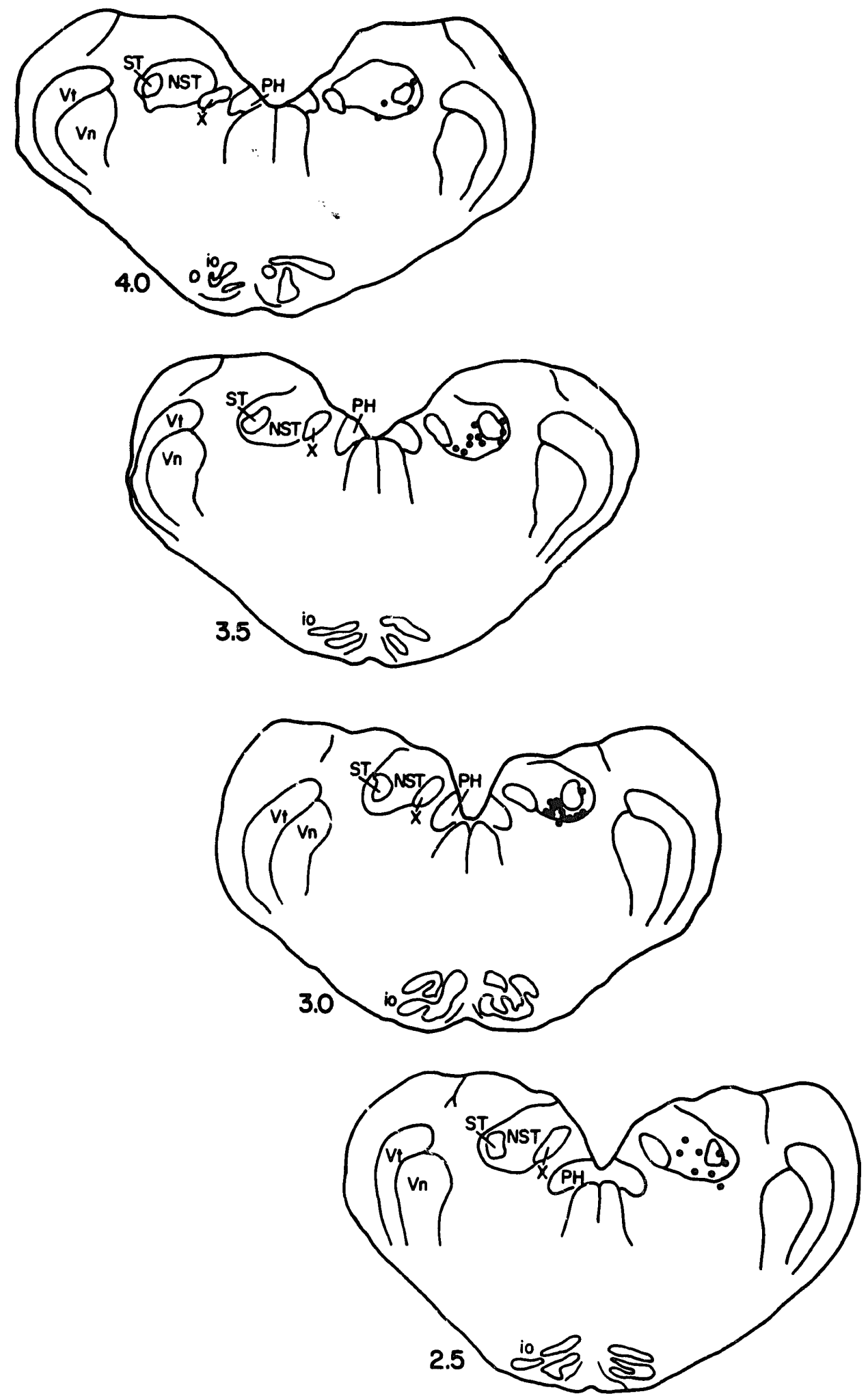

Fig. 1. Anatomical reconstruction of recording sites in the caudal lamb brainstem. Recording sites, represented by filled circles, were generally located in the medial, ventral or lateral areas of the NST. Distances rostral to obex (in mm) of each of the representative brainstem sections are given to the lower left of each section. io, inferior olive; NST, nucleus of the solitary tract; PH, prepositus hypoglossi; ST, solitary tract; $\mathrm{Vn}$, trigeminal nucleus; $\mathrm{Vt}$, trigeminal tract; $\mathrm{X}$, dorsal motor nucleus of the vagus. 


\section{0 cc rinse}

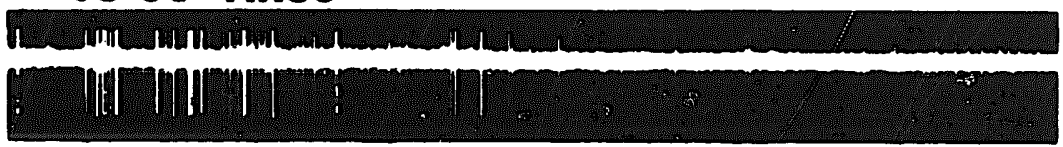

\section{0 cc rinse}
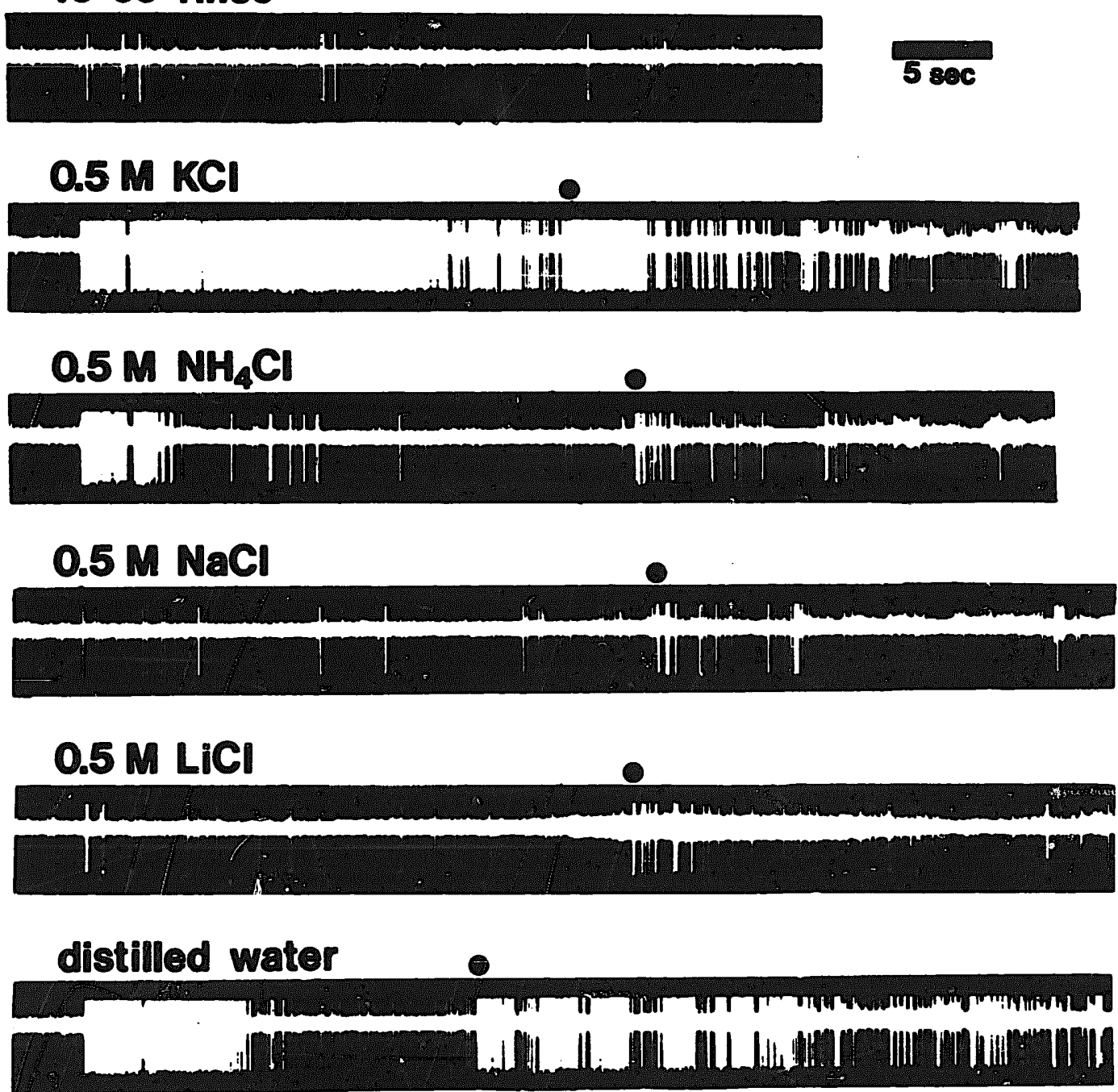

\subsection{M citric acid}

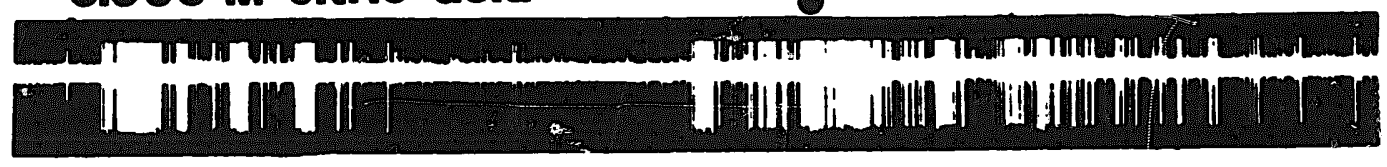

\section{$0.01 \mathrm{~N} \mathrm{HCl}$

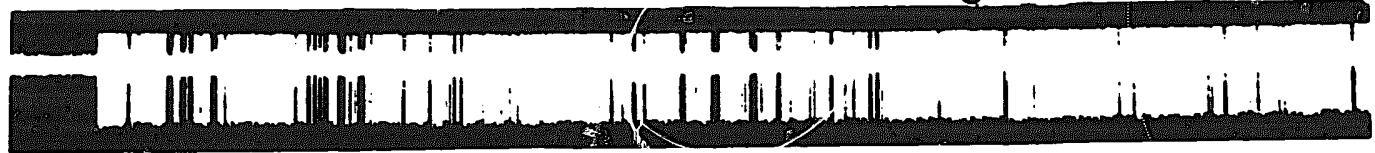

Fig. 2. Oscillographic tracings of the responses of a single NST neuron to stimulation of the epiglottis with different chemical stimuli. The arrow at lower left corner indicates the time of stimulus onset and the filled circles above each record represent the beginning of the $0.154 \mathrm{M} \mathrm{NaCl}$ rinse. At the top of the figure are the responses to the flow of a solution produced by delivering the rinse volume of 10 or $40 \mathrm{ml}$. The responses to the different chemical stimuli are quite distinct. 
neurons isolated in the present study are shown in Fig. 1. Neurons were located in or immediately ventral to the NST between 2.1 and $4.1 \mathrm{~mm}(\overline{\mathrm{x}}=3.21 \pm$ 0.45 S.E.M.) rostral to obex, $2.5-4.5 \mathrm{~mm}(\overline{\mathrm{x}}=3.38$ $\pm 0.51)$ lateral to the midline and $1.5-3.7 \mathrm{~mm}(\overline{\mathrm{x}}=$ $2.37 \pm 0.51)$ ventral to the dorsal surface of the medulla. The majority of neurons were located in the medial or ventral NST with the greatest concentration in an area just ventromedial to the solitary tract.

\section{General response characteristics}

For neurons in the NST, both $\mathrm{KCl}$ and $\mathrm{NH}_{4} \mathrm{Cl}$ were the most effective stimuli, eliciting responses in $89 \%$ of the neurons. Distilled water produced responses in $86 \%$ of the neurons, while $\mathrm{HCl}$ and citric acid produced responses in $77 \%$ and $57 \%$ of the neurons, respectively. The two remaining salts were somewhat less effective with $\mathrm{NaCl}$ evoking responses in $57 \%$ of the neurons and $\mathrm{LiCl}$ eliciting responses in only $40 \%$
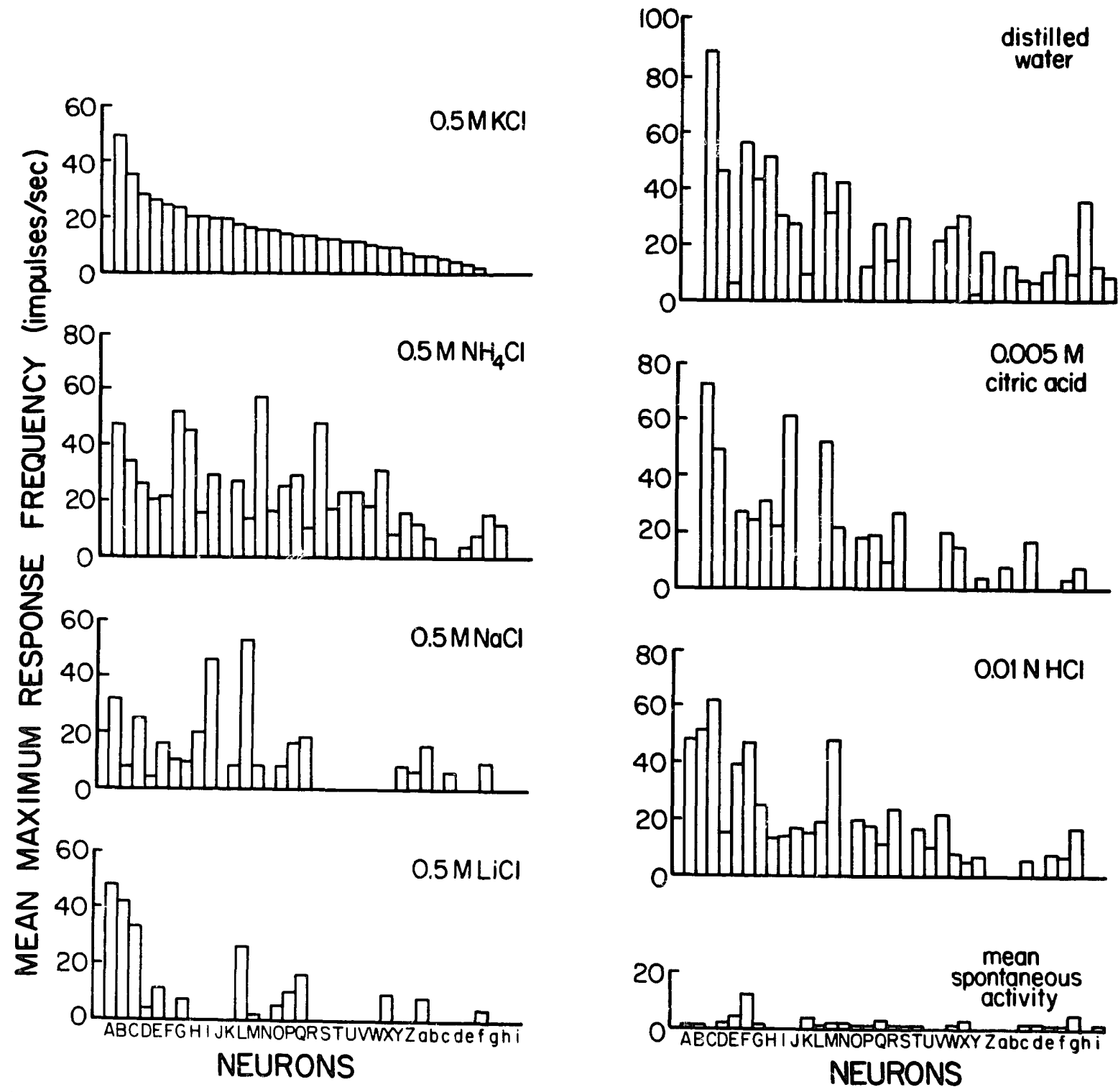

Fig. 3. Maximum response frequencies from lamb single NST neurons. The neurons (A through $i$ ) have been ranked in the order of the maximum response frequency to $\mathrm{KCl}$. Responses for any one neuron can be read in a vertical column. For each neuron, the mean spontaneous activity (plotted at the bottom right of the figure), and the response due to the mechanical effects of stimulus flow have been subtracted. Thus, the response to chemical stimulation only is presented. 

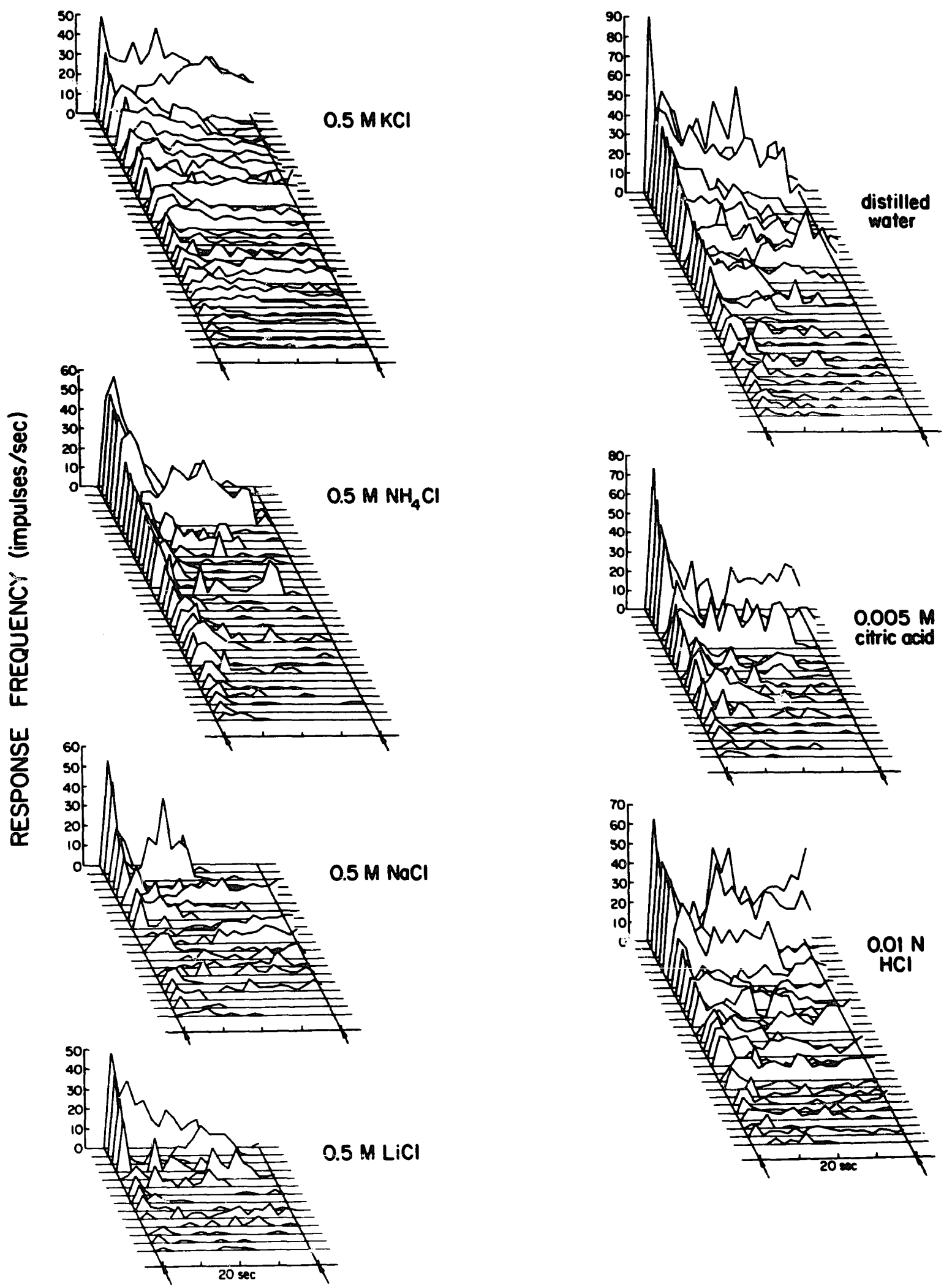

Fig. 4. Frequency-time histograms for responses from lamb NST neurons to the 7 stimuli. Neurons which responded to the different chemical stimuli are arranged in order of increasing maximum frequency from the front to the bark of each histogram. Stimulation time is shown between the two arrows on the abscissa of each histogram and frequency on the ordinate. The spontaneous activity and response due to mechanical effects of stimulus flow have been subtracted from each histogram. 
of the isolated cells. An example of a NST neuron's responses to the different chemical stimuli is shown in Fig. 2. The flow of the rinse produced a small response that was dependent upon the rate of delivery as shown in the top two oscillographic tracings. Applications of boch $\mathrm{KCl}$ and $\mathrm{HCl}$ produced increases in activity, with the siong sustained response to $\mathrm{HCl}$ continuing for over $15 \mathrm{~min}$ even following repeated applications of the rinse. The neural responses to $\mathrm{NH}_{4} \mathrm{Cl}$, distilled water and citric acid were of smaller magnitude, but an off response to the rinse was observed following two of these stimuli. This cell did not respond to either $\mathrm{NaCl}$ or $\mathrm{LiCl}$. Also evident in Fig. 2 is that different chemical stimuli evoked different neural response patterns.

Fig. 3 shows the nean maximum responses of single NST neurons to the various chemical stimuli. Because $\mathrm{KCl}$ was the most effective stimulus, and to permit comparison with previously published results of SLN responses, neurons are ordered by their maximum response frequency to $\mathrm{KCl}$. The mean spontaneous rate was $7.69 \pm 11.05$ impulses $/ 5 \mathrm{~s}$. All but two neurons responded to more than one of the chemical stimuli $(\overline{\mathrm{x}}=4.9 \pm 1.8)$. The remaining two neurons responded exclusively to distilled water. In addition to a response to chemical stimuli, $80 \%$ of the neurons were excited by mechanical stimulation of the epiglottis with a soft brush and $57 \%$ were sensitive to the flow of the rinse. In all cases, neurons displaying a flow response also responded to mechanical stimulation.

\section{Response patterns in the NST}

The response patterns of all neurons to the different chemical stimuli are presented in Fig. 4. These responses were ranked in order of increasing maximum response frequency for each chemical. It can be seen that the responses to an individual chemical across the population of neurons were quite similar. For example, the response pattern elicited by $\mathrm{KCl}$ is generally sustained across the stimulation period whereas the pattern produced by $\mathrm{NH}_{4} \mathrm{Cl}$ rises to an initial peak and quickly returns to the resting level of activity.

The results of the Hotelling's $T^{2}$-test on the response profiles of NST neurons are presented in Table I. The pairs of chemicals that have dissimilar response patterns $(P<0.10)$ are indicated in the table with the significant levels shown. For example, Table I shows that the neural response patterns produced by $\mathrm{KCl}$ were significantly different from the response patterns produced by all other chemical stimuli. In contrast, the pattern produced by citric acid appears to be less distinct with only 2 of the 6 comparisons being significantly different. Furthermore, Table I shows that for most stimuli with significantly different neural response patterns, the first $\mathbf{1 0}$ $s$ were generally the most important, with the response patterns across the last $10 \mathrm{~s}$ being more similar.

Past studies of chemically elicited responses in the lingual gustatory system often use data from stimulus presentations of shorter periods than those used in the present study. Therefore, to investigate whether analyzing a shorter period of response would adversely affect discrimination among response patterns, we conducted an additional analysis using just the first $5 \mathrm{~s}$ of the response. We observed no loss in the discriminability among response patterns when only the first $5 \mathrm{~s}$ of the response was used. However, the first $5 \mathrm{~s}$ of the distilled water and $\mathrm{HCl}$ response patterns were considered different $(P<0.025)$, whereas these two patterns were considered parallel when longer periods of the response patterns were analyzed (Table I).

\section{Rhythmically firing neurons}

Five neurons (14\%) had a rhythmical discharge to chemical stimulation of the epiglottis. We visually observed that these rhythmical responses appeared to be coordinated with spontaneous respiration (none of these neurons were from artificially ventilated animals) and all neurons appeared to fire in phase with inspiration. However, no attempt was made to match the neural response with the exact phase of respiration. Two of the 5 neurons also showed rhythmical spontaneous discharge while the other 3 showed no rhythmicity except in their response to chemical stimulation of the epiglottis. An example of one of these latter neurons is shown in Fig. 5. This figure illustrates that the response patterns characteristic of certain stimuli observed in non-rhythmical neurons $\left(\mathrm{KCl}\right.$ sustained, $\mathrm{NH}_{4} \mathrm{Cl}$ transient; see also Fig. 2) were also observed in neurons with rhythmical responses.

Examination of the recording sites of these 5 neu- 
TABLE I

Comparison of NST neural response patterns between different pairs of chemical stimuli

For each stimulus pair that produces significantly different patterns, the $P$ value is presented in the table. A dash indicates that the stimuli elicit similar (parallel) response patterns $(P>0.10)$. The first row for each chemical represents the comparison for the first $10 \mathrm{~s}$. the second row the comparison for the last $10 \mathrm{~s}$.

\begin{tabular}{|c|c|c|c|c|c|c|}
\hline & $\mathrm{NH}_{4} \mathrm{Cl}$ & $\mathrm{NaCl}$ & $\mathrm{LiCl}$ & $\mathrm{H}_{2} \mathrm{O}$ & $\mathrm{HCl}$ & Citric acid \\
\hline $\mathrm{KCl}$ & 0.001 & 0.016 & 0.050 & 0.002 & 0.084 & 0.009 \\
\hline & 0.002 & - & 0.005 & 0.060 & $\overline{0} 015$ & - \\
\hline $\mathrm{NH}_{4} \mathrm{Cl}$ & & - & - & $\begin{array}{l}0.013 \\
0.098\end{array}$ & $\begin{array}{l}0.015 \\
0.014\end{array}$ & - \\
\hline $\mathrm{NaCl}$ & & & - & - & 0.097 & - \\
\hline & & & - & - & - & - \\
\hline $\mathrm{LiCl}$ & & & & - & 0.093 & - \\
\hline $\mathrm{H}_{2} \mathrm{O}$ & & & & - & $\overline{-}$ & $\overline{0.017}$ \\
\hline & & & & & - & - \\
\hline$\pi$ & & & & & & $\overline{-}$ \\
\hline
\end{tabular}

rons revealed that 4 of the 5 were located in the ventral and ventrolateral NST with the remaining neuron located in the medial region of the nucleus.

\section{Comparison between NST and SLN response patterns}

The mean response profiles for the different chemical stimuli for both NST neurons and SLN fibers ${ }^{13}$ are shown in Fig. 6. Each graph shows the mean response patterns to a different chemical stimulus. Note that for most stimuli the mean response profiles are quite similar.

The results of the profile analysis comparing mean response patterns of SLN fibers $(n=59)$ with NST neurons for each chemical stimulus are presented in Table II. For all stimuli except $\mathrm{NH}_{4} \mathrm{Cl}$ the neural response patterns observed in the NST were not significantly different from the response patterns reported for SLN fibers $(P>0.10)$. In contrast to the other chemical stimuli, the response pattern to $\mathrm{NH}_{4} \mathrm{Cl}$ in the population of NST neurons was different from that observed in the SLN. Further analysis revealed that this difference was due to the central and peripheral responses being shifted in time; the SLN response pattern reached its peak level of activity and returned to its spontaneous activity level later in time (see Fig. 6). When the SLN response pattern is shifted in time to overlap that observed in the NST, the two patterns were parallel (one-way profile analysis, $P>0.10)$.

\section{Off responses}

In addition to responses to the chemical stimuli, 11 of the 35 neurons showed enhanced responses to the $0.154 \mathrm{M} \mathrm{NaCl}$ rinse which followed one or more of the chemical stimuli. An example of one of these off responses is graphically shown in Fig. 7. This figure shows the off responses of a NST neuron elicited by applications of the $0.154 \mathrm{M} \mathrm{NaCl}$ rinse following the stimuli noted in the upper left corner of each graph. Those portions of the response due to the mechanical effects of rinse flow have been subtracted from each of the off responses. For the neuron in Fig. 7, rinses following $\mathrm{NH}_{4} \mathrm{Cl}$, distilled water, citric acid and $\mathrm{HCl}$ evoked off responses.

Most off responses were observed following distilled water $(82 \%)$ or $\mathrm{HCl}(64 \%)$. Of the 11 neurons 4 showed off responses exclusively following distilled water and 2 showed increases to the rinse exclusively following $\mathrm{HCl}$. Only a small number of off responses were observed following citric acid $(27 \%), \mathrm{KCl}$ (18\%) and $\mathrm{NH}_{4} \mathrm{Cl}(18 \%)$, and no off responses were observed following either $\mathrm{NaCl}$ or $\mathrm{LiCl}$.

\section{DISCUSSION}

\section{Response patterns of NST neurons}

The chemosensitive response patterns across the population of isolated NST neurons to an individual chemical stimulus were quite similar. Response pat- 
40 cc rinse

IIII IIIIII II IIIL

\section{0 cc rinse}

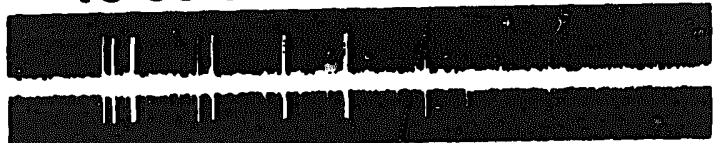

\section{5 sec}

\section{$0.5 \mathrm{M} \mathrm{KCl}$} -

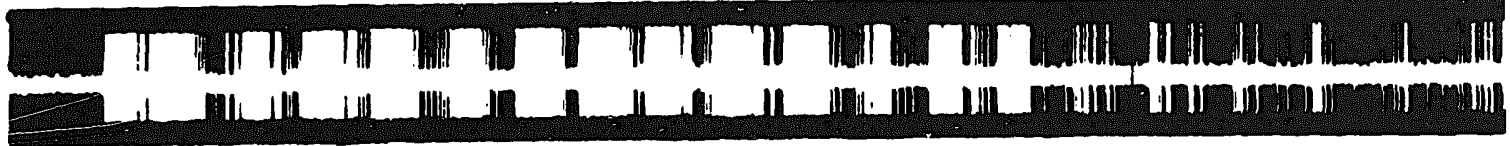

\section{$0.5 \mathrm{M} \mathrm{NH}_{4} \mathrm{Cl}$} -

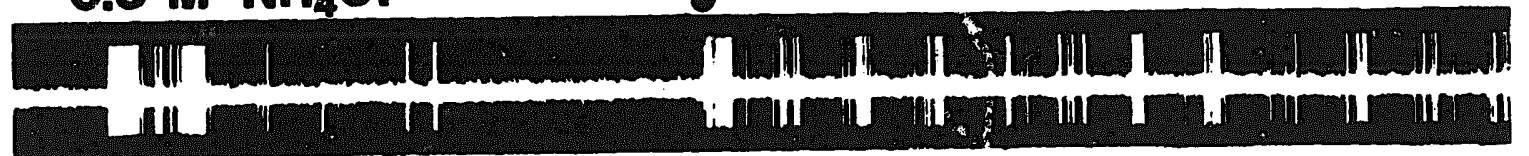

\section{$0.5 \mathrm{M} \mathrm{NaCl}$}

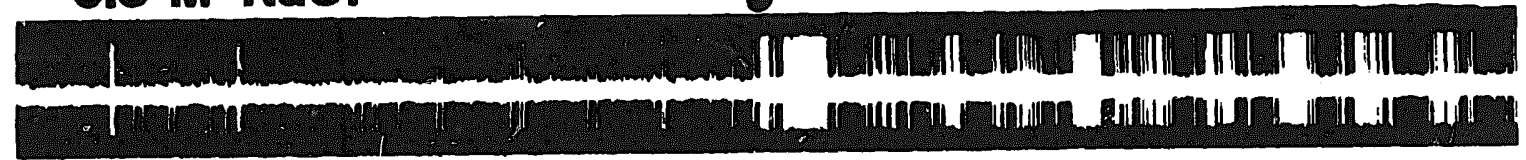

\section{$0.5 \mathrm{M} \mathrm{LiCl}$}

-

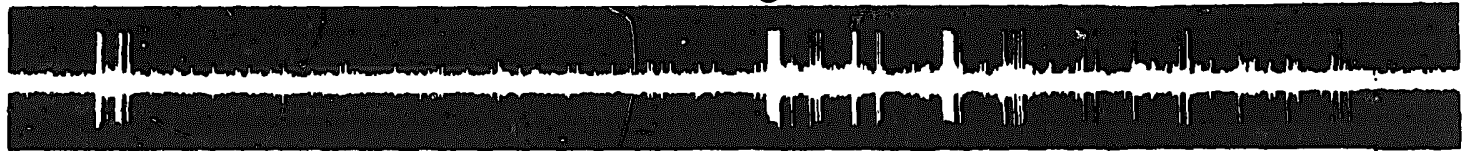

\section{distilled water}

?

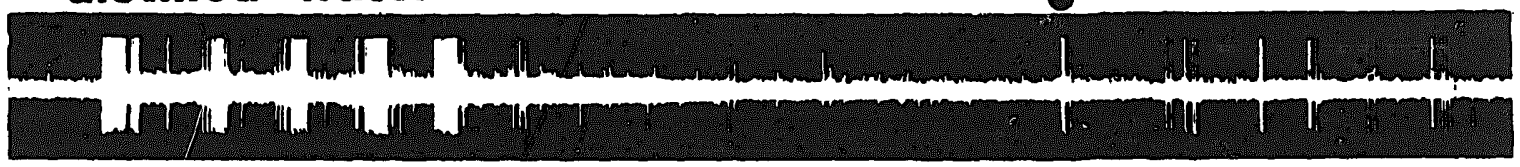

\subsection{M citric acid}

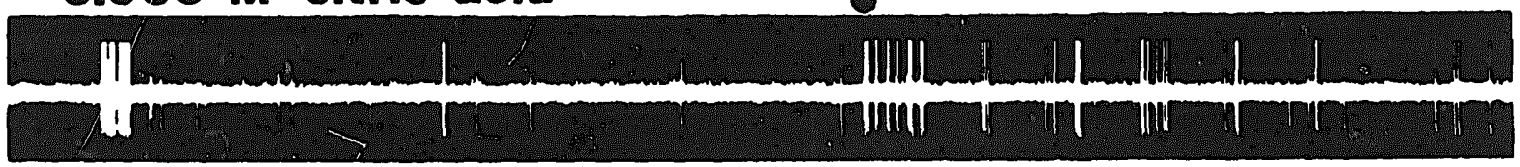

\section{$0.01 \mathrm{~N} \mathrm{HCI}$}

-

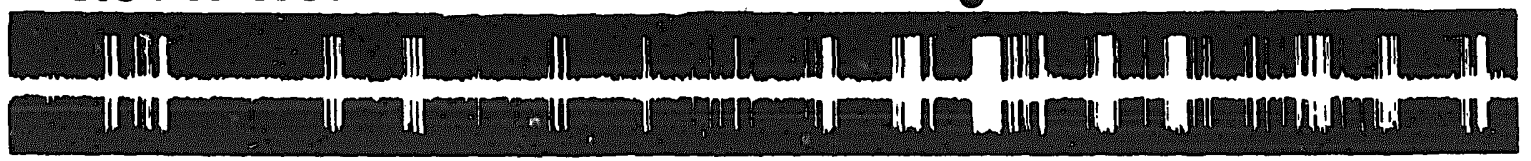

Fig. 5. Oscillographic-tracings of the response of a neuron in the NST to stimulation of the epiglottis with different chemical solutions. This neuron had a rhythmic response that appeared coordinaieu wiii Icspiration. The arrow indicates stimulus onset and the filled circles above each tracing represent the rinse-onset. 
terns characteristic of individual chemical stimuli were also observed in the single fibers isolated from the lamb SLN ${ }^{13}$. As was the case for the SLN, statistical analysis of differences in response patterns for pairs of chemicals over time reveaied that many of
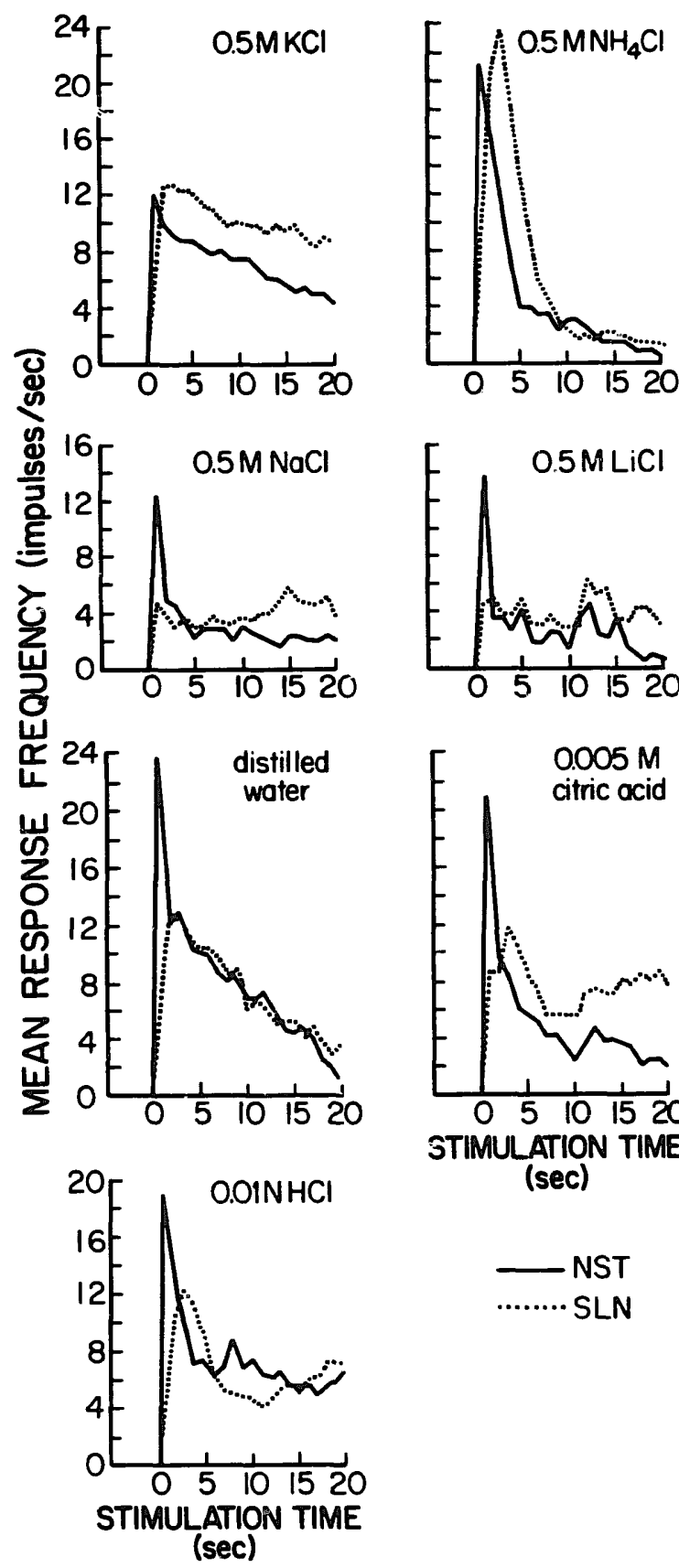

Fig. 6. Comparisons between NST neurons $(n=35)$ and SI.N fibers ${ }^{13}(n=59)$ average response patterns for the different chemical stimuli. The average response pattern across NST neurons is shown by the solid line and across the SLN by the dotted line. Note the large degree of similarity in the response profiles of SLN fibers and NST neurons for each of the chemical stimuli.
TABLE II

Response profile comparison between NST and SLN for matched pairs of chemical stimuli

\begin{tabular}{lll}
\hline & Parallel profiles & Pvalue \\
\hline $\mathrm{KCl}$ & yes & 0.838 \\
$\mathrm{NH}_{4} \mathrm{Cl}$ & no & 0.007 \\
$\mathrm{NaCl}$ & yes & 0.485 \\
$\mathrm{LiCl}$ & yes & 0.241 \\
$\mathrm{H}_{2} \mathrm{O}$ & yes & 0.535 \\
$\mathrm{Citric}$ acid & yes & 0.201 \\
$\mathrm{HCl}$ & yes & 0.148 \\
\hline
\end{tabular}

these patterns in the NST were in fact distinguishable from each other. In both the NST and SLN the chemosensitive response patterns elicited by $\mathrm{KCl}$ were distinct from the patterns produced by all other chemical stimuli. The pattern of neural activity produced by $\mathrm{NH}_{4} \mathrm{Cl}$ was somewhat less distinctive in NST neurons than in fibers of the SLN (6 of 6 comparisons in $\mathrm{SLN}^{13}$ versus 3 of 6 in the NST), while the pattern produced by citric acid was rarely seen as different from the other stimuli in both NST and SLN analyses.

The loss of some discrimination between different chemical stimuli at the level of the NST has also been observed in the rat lingual gustatory system. Using different analytical techniques, Doetsch and Erickson ${ }^{15}$ reported that there was an increasing similarity between the across-ricuron response patterns in NST when compared to the chorda tympani. The increased similarity between some of the chemosensitive response patterns observed in the NST probably reflects the process of excitatory and inhibitory synaptic interactions resulting from convergence of SLN fibers onto second-order neurons in the NST ${ }^{15.20 .44 .55}$.

In the present study we have investigated the response patterns over a relatively long period of time (20 s). However, in studies of gustatory processing involving lingual receptors, data from stimulus presentations of shorter periods are often used ${ }^{17.19 .55}$. Analyzing just the first $5 \mathrm{~s}$ of the response patterns revealed that these patterns were still distinguishable and, in fact, a small amount of additional distinctiveness among stimulus response patterns was observed. Thus, even at shorter intervals the ability to discriminate between the patterns of response observed in our NST sample are maintained.

Most of the chemical stimuli elicited similar neural 

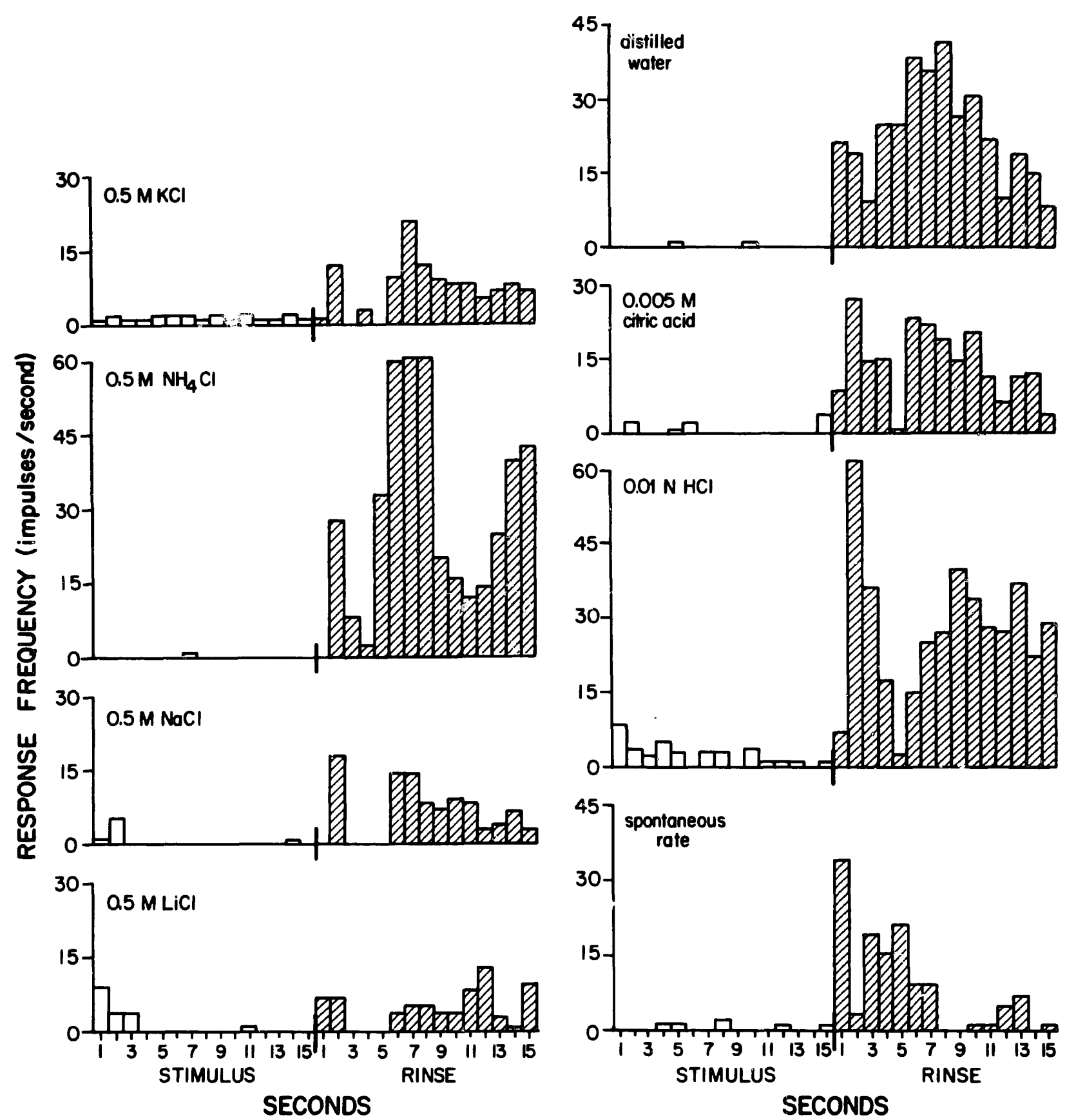

Fig. 7. Off responses of a NST neuron elicited by the application of $0.154 \mathrm{M} \mathrm{NaCl}$ rinse to the epiglottis following different chemical stimuli. On the left of each histogram the last $15 \mathrm{~s}$ of response to each chemical stimulus is shown (open bars), followed on the right by the first $15 \mathrm{~s}$ of response to $0.154 \mathrm{M} \mathrm{NaCl}$ rinse applied after the chemical stimulus (shaded bars). Shown at the bottom right of the figure for comparison is the neuron's spontaneous rate and the mechanical response produced by flowing the rinse over the epiglottis. Those portions of the off responses due only to the mechanical effects of solution flow, and the spontaneous activity of the neuron have been subtracted from each response. For this neuron, off responses which exceeded the response criterion were observed following $\mathrm{NH}_{4} \mathrm{Cl}$, distilled water, citric acid and $\mathrm{HCl}$.

response patterns in the SLN and NST. For example, a sustained response was characteristic of $\mathrm{KCl}$ both peripherally and centrally. Statistical comparisons between the mean chemosensitive response patterns of the SLN and NST for each stimulus demonstrated that except for $\mathrm{NH}_{4} \mathrm{Cl}$, the response patterns were of the same shape (parallel). Although the average response profiles to $\mathrm{NH}_{4} \mathrm{Cl}$ in the NST and SLN were considered different by the present analysis, further investigation revealed that the profiles were shifted 
in time with the NST pattern reaching its peak response frequency faster than that observed in the SLN. The tendency of the NST neurons in the current study to reach their peak response frequency more quickly than SLN fibers was not restricted to $\mathrm{NH}_{4} \mathrm{Cl}$. As is evident in Fig. 6, the average response patterns across NST neurons for all the stimuli tended to reach their peak response frequency more quickly than previously observed for fibers of the SLN. The differences in the time to reach peak response frequency between the NST and SLN were probably the result of the differences in stimulation techniques used in the two studies. In the current study the prone position of the animal necessitated applying solutions at a faster velocity than that used in studies of the SLN where the animal was in a supine position which permitted stimulus delivery via a gravity flow system. Investigating the sensitivity of the rat lingual gustatory system to the onset rate of electrical and chemical stimuli, Smith and Bealer ${ }^{48}$ reported that the transient, but not the tonic portion of the neural response, was extremely sensitive to the rate of stimulus onset. For example, the faster the velocity of stimulus flow to the tongue, the faster the transient portion of the neural discharge in the chorda tympani nerve reached its peak ${ }^{48}$. Since the average $\mathrm{NH}_{4} \mathrm{Cl}$ response patterns in both the NST and SLN were primarily transient in nature, the effects of the different flow velocities on the profile analysis were more pronounced. For the other stimuli, the tonic porticns of the response patterns would tend to Inask initial differences in the transient portion of the response, especially since the first second of the average response patterns was dropped from the analysis. Thus, the patterns of neural activity characteristic of a chemical stimulus in the periphery appear for the most part to be maintained at the level of the NST.

\section{Off responses}

Off responses to the $0.154 \mathrm{M} \mathrm{NaCl}$ rinse were observed following at least one of the stimuli in over $31 \%$ of the NST neurons. The majority of these off responses followed stimulation of the epiglottis with distilled water or $\mathrm{HCl}$. Similar increases in the response to saline rinse following chemical stimulation have been observed in fibers of the SLN ${ }^{\mathrm{i} 0.53}$ (unpublished observation).

Off responses are not unusual in the lingual gusta- tory system for which distilled water is generally used as the rinse solution. Applications of the distilled water rinse following stimulation of the tongue with chemical solutions produces off responses in the peripheral gustatory nerves of a number of different species ${ }^{2.35 .25 .42 .58 .59}$. Some investigators have suggested that these off responses represent a true response to water ${ }^{25.60}$. Others have demonstrated that neural responses to water rinse on the tongue were dependent upon the preceding, adapting stimulus ${ }^{2.3 .42}$. If $0.154 \mathrm{M} \mathrm{NaCl}$ is acting on the receptors of the epiglottis in a manner like that described for water on the tongue ${ }^{2.3 .42}$, then instead of the responses to water after $\mathrm{NaCl}$ or $\mathrm{HCl}$ which are observed for the lingual gustatory system, neurons with epiglottal receptive fields respond to $0.154 \mathrm{M} \mathrm{NaCl}$ after water or $\mathrm{HCl}$.

Various proposals concerning the mechanisms responsible for the water response in the lingual gustatory system suggest that these off responses might result from the removal of chemicals from the receptors $^{1.4 .6}$. If the off responses of NST neurons reflect similar mechanisms, these off responses could provide important information for the control of upper airway reflexes by signaling the removal of chemical substances from the entrance to the upper airway.

\section{Anatomical organization}

The locations of NST recording sites in the present study correspond with the areas of SLN termination in the solitary nucleus of lamb and sheep ${ }^{14.28 .54}$, as well as those areas of SLN termination observed in anatomical studies using cat, rat and hamster ${ }^{21}, 2.38$. The largest number of neurons were isolated in the medial and ventromedial areas of the lamb NST. These areas receive dense terminations of the SLN in both lamb ${ }^{54}$ and hamster ${ }^{22}$, and responses to chemical stimulation of the cat epiglottis have been recorded in these areas as well (unpublished observations). The medial and ventromedial NST also respond to electrical stimulation of the $\operatorname{SLN}^{14.29 .39}$, and have been identified as an important source of efferent fibers to nuclei involved in the control of laryngeal and pharyngeal musculature ${ }^{43}$. Furthermore. studies of the swallowing reflex in sheep have shown that the areas of the NST where many of our recording sites were located are important for the initiation and organization of the buccopharyngeal and esoph- 
ageal phases of swallowing in this species ${ }^{27-29}$.

Fewer neurons were isolated in the ventral, ventrolateral and dorsolateral areas of the NST. The ventral and ventrolateral regions of the NST are known to contain cells involved in respiratory functions ${ }^{26.32 .33 .37 .46}$, and of the 5 neurons in the present study that had their responses coordinated with respiration, all but one were located in these areas. Studies have shown that both electrical stimulation of the SLN and infusions of solutions into the larynx influence respiratory-related neurons in the $\mathrm{NST}^{7.37}$. 41.45.46. The rhythmical neurons observed in the NST probably play an important role in the respiratory effects produced by laryngeal stimulation.

\section{Chemical responses and reflexes of the upper airway}

Studies in a variety of species have documented the reflex swallowing, respiratory and cardiovascular effects produced by infusions of water and chemical stimuli into the larynx $x^{18,23,30.35-37.46,47.53}$. In the current study we have demonstrated that the neural response patterns generated by chemical stimulation of the epiglottis which are observed in the $\operatorname{SLN}^{13}$ are maintained at the level of the NST. Since the region of the NST sampled in the present study is considered an important link in the decoding of afferent information essential to swallowing and other protective airway reflexes, the neural patterns relevant to particular stimuli appear to be transmitted intact to regions influential to the organizatio: of these reflexes.

Although the chemically elicited response patterns

\section{REFERENCES}

1 Bartoshuk, L.M., $\mathrm{NaCl}$ thresholds in man: thresholds for water taste or $\mathrm{NaCl}$ taste? J. Comp. Physiol. Psychol., 87 (1974) 310-325.

2 Bartoshuk, L.M., Harned, M.A. and Parks, L.H., Taste of water in the cat: effects on sucrose preference, Science, 171 (1971) 699-701.

3 Bartoshuk. L.M. and Pfaffmann, C., Effects of pre-treatment on the water taste response in cat and rat, Fed. Proc. Fed. Am. Soc. Exp. Biol., 24 (1965) 207.

4 Beidler, L.M., A theory of taste stimulation, J. Gen. Physiol.. 38 (1954) 133-139.

5 Beidler, L.M., Taste receptor stimulation. In J.A.V. Butler, H.E. Huxley and R.E. Zirkle (Eds.), Progress in Biophysics and Biophysical Chemistry, Vol. XII, Pergamon, New York, 1961, pp. 107-151.

6 Beidler, L.M., Anion influences on taste receptor response. In T. Hayashi (Ed.), Olfaction and Taste, Vol. II, in the NST were often statistically different, these patterns need not be behaviorally relevant. However, a behavioral study by Kovar et al. ${ }^{35}$ suggests that these response patterns may be important in the reflex responses produced by infusions of chemical stimuli into the upper airway. Using a quantitative scoring system to measure apnea and swallowing, Kovar et al. reported a quantitative separation in the levels of apnea (or swallowing) produced by infusions of equimolar concentrations of $\mathrm{NaCl}, \mathrm{LiCl}$ and $\mathrm{CaCl}_{2}$. For example, $\mathrm{NaCl}$ was more effective than $\mathrm{CaCl}_{2}$ in eliciting apnea and swallowing. Results foliowing infusions of acids were similar to those seen for salts, with acetic acid more effective than $\mathrm{HCl}$ in producing both reflex swallowing and apnea ${ }^{35}$.

Wa have observed differences in the patterns of activity of NST neurons which were dependent upon stimulus quality suggesting that these NST neurons may provide a subsirate for the behavioral observations reported by Kovar et al. ${ }^{35}$. Thus, reflex apnea and swallowing initiated by introduction of fluids into the larynx may be in part due to the chemical information from taste buds on the epiglottis relayed to reflex-important areas of the NST via the SLN.

\section{ACKNOWLEDGEMENTS}

The authors wish to thank Dr. T. Harrison for helpful criticisms in the preparation of this manuscript. This work was supported by NIH Grant DE05728 to R.M.B.

Pergamon, Oxford, 1967, pp. 509-534.

7 Berger, A.J., Dorsal respiratory group neurons in the medulla of cat: spinal projections, responses to lung inflation and superior laryngeal nerve stimulation, Brain Research, 135 (1977) 231-254.

8 Boushey, H.A., Richardson, P.S. and Widdicombe, J.G., Reflex effects of laryngeal irritation on the pattern of breathing and total lung resistance, J. Physiol. (London), 224 (1972) 501-513.

9 Boushey, H.A., Richardson, P.S., Widdicombe, J.G. and Wise, J.C.M., The response of laryngeal afferent fibres to mechanical and chemical stimuli, J. Physiol. (London), 240 (1974) 153-175.

10 Bradley, R.M., The role of epiglottal and lingual chemoreceptors: a comparison. In J.E. Steiner and J.R. Ganchrow (Eds.), Determination of Behaviour by Chemical Stimuli, IRL Press, London, 1982, pp. 37-45.

11 Bradley, R.M., Tapping into the brain, Microcomputing, 62 (1982) 72-79. 
12 Bradley, R.M.. Cheal, M.L. and Kim, Y.H., Quantitative analysis of developing epiglottal taste buds in sheep. $J$. Anat., 130 (1980) 25-32.

13 Bradley, R.M., Stedman. H.M. and Mistretta, C.M., Superior laryngeal nerve response patterns to chemical stimulation of sheep epiglottis. Brain Research, 276 (1983) 81-93.

14 Car, A. and Jean, A., Potentiels évoqués dans le rhombencéphale du mouton par la stimulation du ferf laryrigé supérieur. Contribution à l'étude de la localisation du centre déglutiteur, J. Physiol. (Paris), 63 (1971) 715-730.

15 Doetsch, G.S. and Erickson, R.P., Synaptic processing of taste-quality information in the nucleus tractus solitarius of the rat, J. Neurophysiol., 33 (1970) 490-507.

16 Doty, R.W., Neural organization of deglutition. In C.F. Code (Ed.), Handbook of Physiology, Sect. 6 Alimentary Canal, Vol. 4, Am. Physiol. Soc., 1968, pp. 1861-1902.

17 Erickson, R.P., Doetsch. G.S. and Marshall, D.A., The gustatory neural response function, J. Gen. Physiol., 49 (1965) 247-263.

18 Grogaard, J., Lindstrom, D.P., Stahlman. M.T., Marchal, F. and Sundell, H., The cardiovascular response to laryngeal water administration in young lambs, J. Dev. Physiol., 4 (1982) 353-370.

19 Halpern, B.P. and Marowitz, L.A., Taste responses to lickduration stimuli, Brain Research, 57 (1973) 473-478.

20 Halpern, B.P. and Nelson, L.M.. Bulbar gustatory responses to anterior and to posterior tongue stimulation in the rat, Am. J. Physiol., 209 (1965) 105-110.

21 Hamilton, R.B. and Norgren, R., Central projections of gustatory nerves in the rat, J. Comp. Neurol., 222 (1984) 560-577.

22 Hanamori, T. and Smith, D.V., Central projections of the hamster superior laryngeal nerve, Brain Res. Bull., 16 (1986) 271-280.

23 Harding, R., Johnson, P., Johnston, B.E., McClelland, M.E. and Wilkinson, A.R., Cardiovascular changes in newborn-lambs during apnoea induced by stimulation of laryngeal receptors with water, J. Physiol. (London), 256 (1976) 35P.

24 Harding, R., Johnson, P. and McClelland, M.E.. Liquidsensitive laryngeal receptors in the developing sheep, cat and monkey, J. Physiol. (Lcndon), 277 (1978) 409-422.

25 Hellekant, G., Electrophysiological investigation of the gustatory effect of ethyl alcohol. II: A single fibre analysis in the cat, Acta Physiol. Scand., 64 (1965) 398-406.

26 Henry, J.L. and Sessle, B.J., Effects of glutamate, substance $P$ and endosin-related peptide on solitary tract neurones involved in respiration and respiratory reflexes, $\mathrm{Neu}$ roscience, 14 (1985) 863-873.

27 Jean, A., Localisation et activité des neurones déglutiteurs bulbaires, J. Physiol. (Paris), 64 (1972) 227-268.

28 Jean, A., Brainstem organization of the swallowing network. Brain Behav. Evol., 25 (1984) 109-116.

29 Jean. A. and Car, A.. Inputs to the swallowing medullary neurons from the peripheral afferent fibers and the swallowing cortical areas, Brain Research, 178 (1979) 567-572.

30 Johnson, P., Robinson, J.S. and Salisbury, D.. The onset and control of breathing after birth. In R.S. Comline (Ed.), Foetal and Neonatal Physiology, University Press, Cambridge, 1973, pp. 217-221.

31 Johnson, P., Salisbury. D.M. and Storey, A.T., Apnoea induced by stimulation of sensory receptors in the larynx. In J.F. Bosma and J. Showacre (Eds.). Development of Upper
Respiratory Anatomy and Function: Implications for Sudden Infant Death Syndrome, U S. Government Printing Office, Washington, DC, 1975, pp. 160-183.

32 Kalia, M., Feldman, J.L. and Cohen. M.I.. Afferent projections to the inspiratory neuronal region of the ventrolateral nucleus of the tractus solitarius in the cat, Brain Research, 171 (1979) 135-141.

33 Kalia, M.P., Anatomical organization of central respicatory neurons, Annu. Rev. Physiol., 43 (1981) 105-120.

34 Klüver, H. and Barrera, E., A method for the combined staining of cells and fibres in the nervous system, J. Neuropathol. Exp. Neurol., 12 (1953) 400-403.

35 Kovar, I., Selstam, U., Catterton. W.Z., Stahlman, M.T. and Sundell, H.W., Laryngeal chemoreflex in newborn lambs: respiratory and swallowing response to salts, acids, and sugars, Pediat. Res., 13 (1979) 1144-1149.

36 Lee, J.C., Stoll, B.J. and Downing. S.E., Properties of the laryngeal chemoreflex in neonatal piglets, Am. J. Physiol., 233 (1977) R30-R36.

37 Lucier, G.E., Storey, A.T. and Sessle, B.J., Effects of upper respiratory tract stimuli on neonatal respiration: reflex and single neuron analyses in the kitten, Biol. Neonate, 35 (1979) 82-89.

38 Lucier, G.L., Egizii, R. and Dostrosky, J.O., Projections of the internal branch of the superior laryngeal nerve of the cat, Brain Res. Bull.. 16 (1986) 713-721.

39 Miller, A.J., Deglutition, Physiol. Rev., 62 (1982) 129-184.

40 Morrixon, D.F., Multivariate Statistical Methods, McGrawHill, New York, 1967, pp. 1-415.

41 Pantaleo. T. and Corda, M., Respiration-related neurons in the medial nuclear complex of the solitary tract of the cat, Resp. Physiol., 64 (1986) 135-148.

42 Pfaffmann. C.. Frank, M., Bartoshuk, L.M. and Snell, T.C., Coding gustatory information in the squirrel monkey chorda tympani. In J.M. Sprague and A.N. Epstein (Eds.), Progress in Psychobiology and Physiological Psychology, Vol. 6, Academic, New York, 1976. pp. 1-27.

43 Ross, C.A., Ruggiero, D.A. and Reis. D.J.. Projections from the nucleus tractus solitarii to the rostral ventrolateral medulla, J. Comp. Neurol., 242 (1985) 511-534.

44 Sessle, B.J., Excitatory and inhibitory inputs to single neurones in the solitary tract nucleus and adjacent reticular formation, Brain Research, 53 (1973) 319-331.

45 Sessle, B.J., Greenwood, L.F. and Kenny, D.J., Influences from upper respiratory tract on caudal brainstem neurones of cat, Can. J. Physiol. Pharmacol., 52 (1974) 895-898.

46 Sessle, B.J.. Greenwood, L.F., Lund, J.P. and Lucier. G.E., Effects of upper respiratory tract stimuli on respiration and single respiratory neurons in the adult cat. Exp. Neurol., 61 (1978) 245-259.

47 Shingai, T. and Shimada, K., Reflex swallowing elicited by water and chemical substances applied in the oral cavity, pharynx. and larynx of the rabbit. Jap. J. Physiol., 26 (1976) 455-469.

48 Smith, D.V. and Bealer. S.L.. Sensitivity of the rat gustatory system to the rate of stimulus onset. Physiol. Behav.. 15 (1975) 303-314.

49 Smith. D.V., Bealer, S.L. and Van Buskirk. R.L., Adaptation and recovery of the rat chorda tympani response to NaCl. Physiol. Behav.. 20 (1978) 629-636.

50 Stedman. H.M.. Bradley. R.M., Mistretta. C.M. and Bradley, B.E.. Chemosensitive responses from the cat epiglottis, Chem. Senses. 5 (1980) 233-245. 
51 Stedman, H.M., Mistretta, C.M. and Bradley, R.M., A quantitative study of cat $c_{p i g l o t t a l}$ taste buds during development. J. Anat., 136 (1983) 821-827.

52 Storey, A.T.. Laryngeal initiation of swallowing, Exp. Neurol., 20 (1968) 359-365.

53 Storey, A.T. and Johnson, P.. Laryngeal water receptors initiating apnea in the lamb, Exp. Neurol., 47 (1975) $42-55$.

54 Sweazey, R.D. and Bradley, R.M., Central connections of the lingual-tonsillar branch of the glossopharyngeal nerve and the superior laryngeal nerve in lamb, J. Comp. Neurol., 245 (1986) 471-482.

55 Sweazey, R.D. and Smith, D.V., Convergence onto hamster medullary taste neurons, Brain Research, 408 (1987)
$173-184$.

56 Travers, J.B. and Smith, D.V., Gustatory sensitivities in neurons of the hamster nucleus tractus solitarius, Sens. Process., 3 (1979) 1-26.

57 Widdicombe, J.G., Receptors in the trachea and bronchi of the cat, J. Physiol. (London), 123 (1954) 71-104.

58 Yamamoto. T. and Kawamura, Y., Studies on a water 'rinse effect' after sucrose application to the tongue of the rat, J. Physiol. Soc. Jap., 33 (1971) 294-302.

59 Yamamoto, T. and Kawamura, Y., An off-type response of the chorda tympani nerve in the rat, Physiol. Behav., 13 (1974) 239-243.

60 Zotterman, Y., Species differences in the water taste, Acta Physiol. Scand., 37 (1956) 60-70. 